\title{
Analytical Artifacts in Radioimmunoassay of L-Thyroxin in Human Milk
}

\author{
J. Mallol, M. J. Obregón, and G. Morreale de Escobar' ${ }^{1}$
}

Previous results are contradictory regarding the concentration of thyroxin in human milk. Using a sensitive radioimmunoassay, we have found a lack of parallelism between the standard curve for thyroxin and the curve for serial dilutions of whole human milk, skimmed milk, or ethanol extracts of milk. Nonspecific binding also indicated the presence of analytical artifacts. Thus we have separated thyroxin from other milk components by means of a strongly basic Bio-Rad anion-exchange resin with quaternary ammonium exchange groups attached to a styrene divinyl benzene copolymer lattice, radioimmunoassaying the fractions eluted with an equivolume mixture of acetic acid and water. Parallelism with the standard curve was good, and results were the same whether or not the resin eluate was further purified by paper chromatography. The range of thyroxin concentration in 21 samples of human milk was 0.29-2.00 $\mu \mathrm{g} / \mathrm{L}$ (mean 0.71, SD 0.40, $\mu \mathrm{g} / \mathrm{L}$ ). Such concentrations are unlikely to afford protection to the developing brain of a breast-fed athyreotic baby, as previously claimed.

Additional Keyphrases: reference interval - disorders of thyroxin production - hypothyroidism - newborns. chromatography, paper - chromatography, anion-exchange

Montalvo et al. (1) and Strbák et al. (2) reported, respectively, 7-96 and 15-130 $\mu \mathrm{g}$ of thyroxin $\left(\mathrm{T}_{4}\right)$ per liter of human milk, as determined with competitive binding assays of whole milk, skimmed milk, or ethanol extracts of milk. Sack et al. (3) and Tenore et al. (4) reported values of 4-70 and 13-80 $\mu \mathrm{g}$ of $\mathrm{T}_{4}$ per liter of human milk, respectively, as measured by radioimmunoassay (RIA). ${ }^{2}$ Such concentrations of $\mathrm{T}_{4}$ might afford a considerable degree of protection to the brain of hypothyroid babies. Indeed, Tenore et al. (4) reported improved mental development in breast-fed, as compared with formula-fed, athyreotic babies and attributed this finding to the higher $\mathrm{T}_{4}$ content of human milk.

These findings contrast with those of Varma et al. (5), who reported the concentration of $\mathrm{T}_{4}$ as determined by RIA to be $<5 \mu \mathrm{g} / \mathrm{L}$ in 83 out of 88 samples of human milk. Sato and $\mathrm{Su}-$ zuki (6) also found $T_{4}$ concentrations of $<5 \mu \mathrm{g} / \mathrm{L}$ in $100 \mathrm{sam}$ ples of human milk, and in trypsin digests of 20 samples. These results are consistent with the report of Tsuyusaki et al. (7), who found that ethanol extracts of human milk had no biological activity as measured by a goiter prevention bioassay.

The aim of the present work was to ascertain which of these contradictory reports is correct. We used a highly sensitive RIA, developed for serum $\mathrm{T}_{4}$ by Weeke and $\emptyset$ rskov (8). None of the 21 samples we have studied so far contains $>2 \mu \mathrm{g}$ of $\mathrm{T}_{4}$

Departamento de Endocrinologia Experimental, Instituto G. Marañon, C.S.I.C y Facultad Autónoma de Medicina, Arzobispo Morcillo 4, Madrid-34, Spain.

1 Address correspondence to this author.

2 Nonstandard abbreviations: $T_{4}$, L-thyroxin; $T_{4}^{*}$, radiolabeled $T_{4}$; PEG, polyethylene glycol.

Received Dec. 17, 1981; accepted Feb. 25, 1982. per liter; thus we conclude that the lower values reported are more nearly correct, but still high.

\section{Materials and Methods}

$T_{4} R I A$. We used the method of Weeke and $\emptyset$ rskov (8) described for assay of $\mathrm{T}_{4}$ in human serum, as modified by Obregón et al. (9), in which RIA buffer is used as the solvent for standards used in preparing the $T_{4}$ standard curve and polyethylene glycol 6000 (PEG) is used to separate free from antibody-bound labeled $\mathrm{T}_{4} \cdot{ }^{125} \mathrm{I}$-labeled $\mathrm{T}_{4}\left(\mathrm{~T}_{4}^{*}\right)$ of high specific activity (2000 Ci/g, or higher) was obtained by the method of Weeke and $\emptyset$ rskov (10) as modified by Kjeld et al. (11). The sensitivity is $5 \mathrm{pg}$ of $\mathrm{T}_{4}$ per tube, $0.5 \mu \mathrm{L}$ of human serum being sufficient.

In brief, the $\mathrm{T}_{4}$ standards, prepared in $50 \mu \mathrm{L}$ of RIA phosphate buffer (40 mmol/L, pH 8.0, and containing $0.6 \mathrm{mmol}$ of thimerosal and $0.5 \mathrm{~g}$ of bovine serum albumin per liter), are pipetted into test tubes. Milk samples are pipetted in quadruplicate at each dilution and diluted to $50 \mu \mathrm{L}$ with the RIA buffer. Three of these quadruplicate tubes receive $100 \mu \mathrm{L}$ of $\mathrm{T}_{4}$ antiserum at a 20000 -fold dilution, and the fourth receives $100 \mu \mathrm{L}$ of buffer. Thus there is an individual "blank" for each triplicate of each dilution of a milk sample. Approximately $7000 \mathrm{cpm}$ of $\mathrm{T}_{4}^{*}$ is added, in $100 \mu \mathrm{L}$ of RIA buffer. After 16 - to 20-h incubation at room temperature, $1.5 \mathrm{~mL}$ of RIA buffer containing $200 \mathrm{~g}$ of PEG and $50 \mathrm{~mL}$ of normal calf serum per liter is added and the tubes and contents are vigorously vortex-mixed for $20 \mathrm{~s}$. After centrifugation at $2000 \mathrm{rpm}$ for $45 \mathrm{~min}$, the supernatant fluid is aspirated and the radioactivity in the precipitate is counted. RIA buffer "blanks" are used to determine the nonspecifically bound $T_{4}^{*}$ for tubes containing $T_{4}$ standards, whereas individual "blanks" are used for milk samples.

Sample-preparation procedure $A$. Whole milk was obtained from volunteers at different times after delivery and stored at $-20^{\circ}$ until used.

Unless whole milk is used directly for the RIA, add about $5000 \mathrm{cpm}$ of $\mathrm{T}_{4}^{*}$ to $1.0 \mathrm{~mL}$ of whole milk. After $2 \mathrm{~h}$ at room temperature, centrifuge the radiolabeled milk for $\mathbf{4 5} \mathrm{min}$ at $2000 \mathrm{rpm}$, or extract it with absolute ethanol. In the first case, separate the skimmed milk from the fat layer at $4^{\circ} \mathrm{C}$. In the second case, add either the same volume of ethanol (1:2 EtOH extract) or nine volumes of ethanol (1:10 EtOH extracts) to whole or skimmed milk, centrifuge, and use the supernate for analysis. Count the radioactivity in aliquots of whole and skimmed milk and of EtOH extracts to determine the $\mathrm{T}_{4}^{*}$ partition and extraction coefficients after the usual corrections for counting geometry, efficiency, etc. After centrifugation of whole milk, dissolve the fat recovered in a volume of $\mathrm{EtOH}$ corresponding to the initial volume of whole milk.

Assay whole or skimmed milk, or EtOH extracts, at three dilutions. Evaporate EtOH extracts to dryness at room temperature under a stream of air. The radioactivity of these samples was $<200 \mathrm{cpm}$ per tube. Follow the above $\mathrm{T}_{4}$ RIA procedure.

Aliquot volumes indicated in Tables and Figures and in the text are given in "equivalents" of whole or skimmed milk. For example, a " $50-\mu \mathrm{L}$ aliquot" of a 1:2 EtOH extract means that $100 \mu \mathrm{L}$ of EtOH was actually evaporated for the RIA; in the 

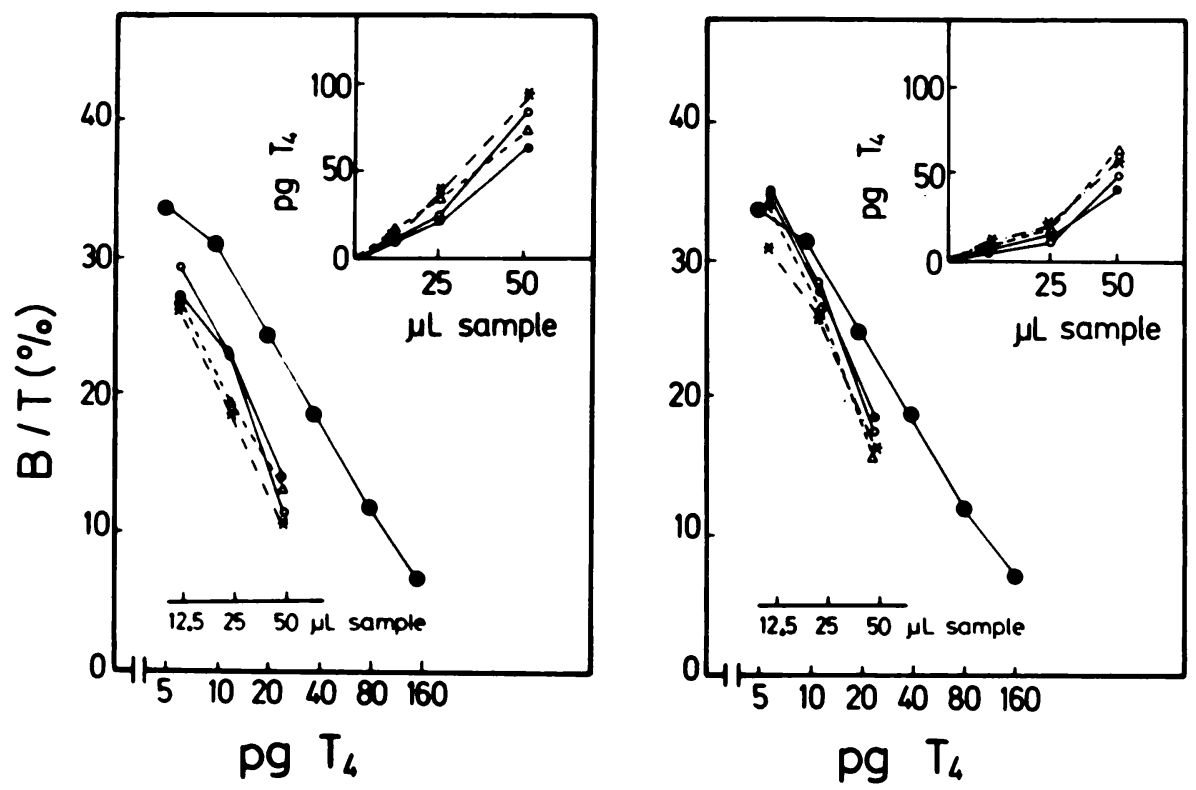

Fig. 1. Serial dilution curves obtained with (left) whole milk and (right) skimmed milk, as compared with the standard curve prepared with use of RIA buffer

Insets: the apparent $T_{4}$ contents as a function of the volume of sample used for the RIA. As may be seen, the data usually do not fall on a straight line passing through the origin. Different symbols are used to identify samples from different milk donors. Results are only shown for four donors, but samples for 15 were tested. Most of these 15 samples did not give dilution curves that paralleled the standard curve

case of milk fat, a " $50-\mu \mathrm{L}$ aliquot" would indicate the fat contained in $50 \mu \mathrm{L}$ of the original whole milk.

Sample-preparation procedure $B$ : isolation of $T_{4}$ by chromatography on Bio-Rad columns. Add $\mathrm{T}_{4}^{*}(7000 \mathrm{cpm})$ to $1.5 \mathrm{~mL}$ of whole milk (or RIA buffer for the "blank" column). After $1 \mathrm{~h}$ at room temperature, pass the mixture through a 1.5-mL column of Bio-Rad $1 \times 2(200-400$ mesh, in chloride form) (12) equilibrated with acetate buffer $(0.2 \mathrm{~mol} / \mathrm{L}, \mathrm{pH}$ 7.0). Wash the column with $2 \mathrm{~mL}$ of the same buffer and then with $4 \mathrm{~mL}$ of EtOH; this removes most of the milk proteins and lipids. Then wash with $2 \mathrm{~mL}$ of acetate buffer $(0.2 \mathrm{~mol} / \mathrm{L})$ at $\mathrm{pH} 4.0$ and $2 \mathrm{~mL}$ at $\mathrm{pH} 3.0$, followed by $2 \mathrm{~mL}$ of $18 \mathrm{mmol} / \mathrm{L}$ $(10 \mathrm{~mL} / \mathrm{L})$ and $2 \mathrm{~mL}$ of $610 \mathrm{mmol} / \mathrm{L}(350 \mathrm{~mL} / \mathrm{L})$ acetic acid. Discard all these eluates. Then pass seven or eight $0.5-\mathrm{mL}$ fractions of $880 \mathrm{mmol} / \mathrm{L}(500 \mathrm{~mL} / \mathrm{L})$ acetic acid through the column, collect the eluates and count the radioactivity of each. Pool the two or three fractions containing the highest radioactivity to obtain "eluate 1." This contains more than half of the $T_{4}^{*}$ that was added to the milk sample and is clear and colorless, even when the milk sample has a high lipid content. Count the radioactivity in an aliquot to determine the analytical recovery of $T_{4}^{*}$. Pipet other aliquots (usually 40 and 80 $\mu \mathrm{L}$ ) in quadruplicate into RIA tubes and evaporate them. Add $50 \mu \mathrm{L}$ of RIA buffer and follow the $\mathrm{T}_{4}$ RIA procedure, except add more $T_{4}^{*}$ than usual (8000-9000 cpm per tube) to minimize the influence of the $200-300 \mathrm{cpm}$ of $\mathrm{T}_{4}^{*}$ in the eluate- 1 aliquots. Calculate the concentration of $\mathrm{T}_{4}$ in the initial milk sample from the amount of $\mathrm{T}_{4}$ found in the aliquot and the recovery of $\mathrm{T}_{4}^{*}$ in a known volume of eluate 1 .

Sample-preparation procedure $C$ : isolation of $T_{4}$ by procedure $B$ and paper chromatography. To validate procedure $B$, evaporate another aliquot of eluate 1 , dissolve the residue in small volumes of methanol/ammonia ( $99 / 1$ by vol), and transfer the solution to Whatman $3 \mathrm{MM}$ paper strips, $2.5-\mathrm{cm}$ wide, previously spotted with $50 \mu \mathrm{L}$ of EtOH containing propylthiouracil, $10 \mathrm{mmol} / \mathrm{L}$, to protect $\mathrm{T}_{4}$ from artifactual de-iodination. Submit the strips to descending chromatography in 2-methylbutanol/hexane/ammonia, $2 \mathrm{~mol} / \mathrm{L}(5 / 1 / 6$ by vol), as described by Bellabarba et al. (13). Dry the chromatograms, cut them into strips $1-\mathrm{cm}$ wide, and count the radioactivity. Pool the two or three strips containing the highest $\mathrm{T}_{4}^{*}$ content and elute them with $2.0 \mathrm{~mL}$ of methanol/ ammonia ("eluate 2"). Count an aliquot for $\mathrm{T}_{4}^{*}$ recovery. Pipet other aliquots (usually 50,100 , and $200 \mu \mathrm{L}$ ) in quadruplicate into RIA tubes and evaporate at room temperature under a stream of air. Perform the RIA and calculate the concentration of $\mathrm{T}_{4}$ in milk, as indicated for procedure $\mathrm{B}$.

Miscellanea: The Bio-Rad resin was washed before the columns were prepared. It was first suspended in $1.2 \mathrm{~mol} / \mathrm{L}$ acetic acid and then washed several times with distilled water until the $\mathrm{pH}$ was 3-4. It then was washed with acetate buffer $(0.2 \mathrm{~mol} / \mathrm{L}, \mathrm{pH} 7.0)$. A resin slurry was poured into $2-\mathrm{mL}$ plastic syringes ( $9 \mathrm{~mm}$ i.d.) up to the $1.5-\mathrm{mL}$ mark. The resin was prevented from passing through the syringe by a $6.3-\mathrm{mm}$ dot of Whatman 3 MM paper. The acetate buffer was drained just before the milk sample was added.

In some cases, Staphylococcus aureus was used instead of PEG. A $100 \mathrm{~g} / \mathrm{L}$ suspension of heat- and formaldehyde-killed bacteria, prepared as described by Kessler (14), was kindly obtained for us by Dr. I. Gil from a protein A-rich Cowan strain. We diluted $15 \mu \mathrm{L}$ of the suspension to $500 \mu \mathrm{L}$ in pH 8

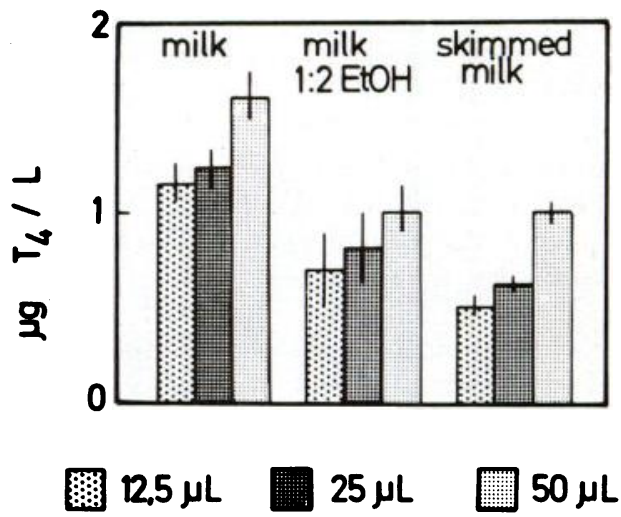

Fig. 2. The apparent $T_{4}$ concentrations found on using different aliquots of whole milk, skimmed milk, or 1:2 EtOH extracts of whole milk

The apparent concentration was not independent of the sample volume. The same was true of 1:2 EtOH extracts of skimmed milk or 1:10 EtOH extracts of whole milk. Data are means \pm SEM of the same samples used for Fig. 1 


\begin{tabular}{|c|c|c|}
\hline \multicolumn{3}{|c|}{$\begin{array}{c}\text { Table 1. Assayed Concentrations of } T_{4} \text { in Whole } \\
\text { Milk, Skimmed Milk, and Milk Fat (col. A), } \\
\text { and Calculated } T_{4} \text { Concentrations in Whole } \\
\text { Milk (col. B) }\end{array}$} \\
\hline Sample in RIA tube & $\begin{array}{c}\text { A: } T_{A}, \\
p g / 50 \mu L\end{array}$ & $\begin{array}{l}\text { B: } T_{A}, \\
\mu g / L C\end{array}$ \\
\hline Whole milk & $80(6)$ & $1.60(0.12)$ \\
\hline 1:10 EtOH extract & $71(7)$ & $1.57(0.16)$ \\
\hline 1:2 EtOH extract & $49(8)^{d}$ & $1.07(0.17)^{d}$ \\
\hline Skimmed milk & $50(3)^{d}$ & $1.42(0.09)$ \\
\hline 1:2 EtOH extract & $52(16)^{d}$ & $1.48(0.41)$ \\
\hline Fat, EtOH extract & $48(7)^{d}$ & $3.22(0.58)^{d}$ \\
\hline \multicolumn{3}{|c|}{$\begin{array}{l}\text { Data are means (and SEM) for samples from the same donors as for Figures } \\
1 \text { and } 2 .{ }^{\circ} \text { Amount of } T_{4} \text { found in the RIA tubes, for } 50 \mu \mathrm{L} \text { of whole or skimmed } \\
\text { milk, the equivalent volumes of EtOH extracts, or the fat corresponding to } 50 \\
\mu \mathrm{L} \text { of whole milk. }{ }^{c} \text { Calculated from the } T_{4} \text { data in column } A \text { and the individual } \\
T_{4}^{\circ} \text { partition and extraction coefficients. }{ }^{d} \text { Significantly }(p<0.05 \text { or better) dif- } \\
\text { ferent from whote milk, as calculated by the paired t-test. }\end{array}$} \\
\hline
\end{tabular}

phosphate buffer, added this to the tubes, and centrifuged at $2000 \mathrm{rpm}$ for $45 \mathrm{~min}$. The supernate was aspirated and radioactivity in the pellet was counted.

Statistical analysis. Mean values and SEM were calculated, and Student's $t$-test was performed, as described by Snedecor (15). The paired $t$-test was used to evaluate the significance of differences between results obtained by different procedures, to account for variability in milk from different donors.

\section{Results}

If the concentrations of $\mathrm{T}_{4}$ in human milk were about the same as those in serum (1-4), 0.5 to $1.0 \mu \mathrm{L}$ of whole milk should suffice for determination of $\mathrm{T}_{4}$ with the present RIA $(8,9)$. But we found that a larger sample volume was necessary before we observed displacement of $\mathrm{T}_{4}^{*}$ in the RIA; when we used more sample, however, there was no parallelism between the $\mathrm{T}_{4}$ standard curve and serial dilutions of most (though not all) of the 15 samples of human milk tested. That is to say, the $\mathrm{T}_{4}$ concentration was not independent of the volume of sample used in the RIA. Moreover, this problem was not solved by using skimmed milk samples or evaporated $\mathrm{EtOH}$ extracts of whole or skimmed milk. This point is illustrated in Figures 1 and $\mathbf{2}$ for four of the samples tested.

\footnotetext{
Table 2. Binding of $T_{4}^{*}$ in the Absence of Anti- $T_{4}$ Antiserum in RIA Tubes Containing Buffer or Samples of Human Milk a

Sample

RIA buffer ${ }^{b}$

Whole milk

1:10 EtOH extract

1:2 EtOH extract

Skimmed milk

1:2 EtOH extract

Milk fat, EtOH extract

\begin{tabular}{lc}
\multicolumn{2}{c}{ \% of $T_{4}^{\circ}$ in the precipltate } \\
\hline \multicolumn{1}{c}{ A } & B \\
$5.2(0.3)$ & $10.1(0.3)$ \\
$5.9(0.1)$ & $19.7(0.8)^{c}$ \\
$7.8(0.6)^{c}$ & $19.9(1.2)^{c}$ \\
$8.5(0.1)^{c}$ & $29.1(5.3)^{c}$ \\
$5.1(1.3)$ & $13.2(3.1)$ \\
$7.8(0.5)^{c}$ & $16.2(3.2)^{c}$ \\
$7.3(0.6)^{c}$ & $46.3(2.5)^{c}$
\end{tabular}

- Data are expressed as percentages of the total $T_{4}^{\circ}$ added, and are means (and SEM) of four samples (same as used for previous Figures and Table). Data in column A were obtained by using PEG, those in column $B$ by using $S$. aureus to separate free from bound $T_{4}^{\circ}$. ${ }^{b}$ The total binding in the presence of anti-T 4 antiserum was $43.4 \pm 1.0 \%$ on using PEG, and $44.3 \pm 1.4 \%$ on using $S$. aurous. $c$ Difference with respect to the values found for blanks (RIA buffer) are statistically significant ( $p<0.05$ or better) by the paired $t$-test.
}

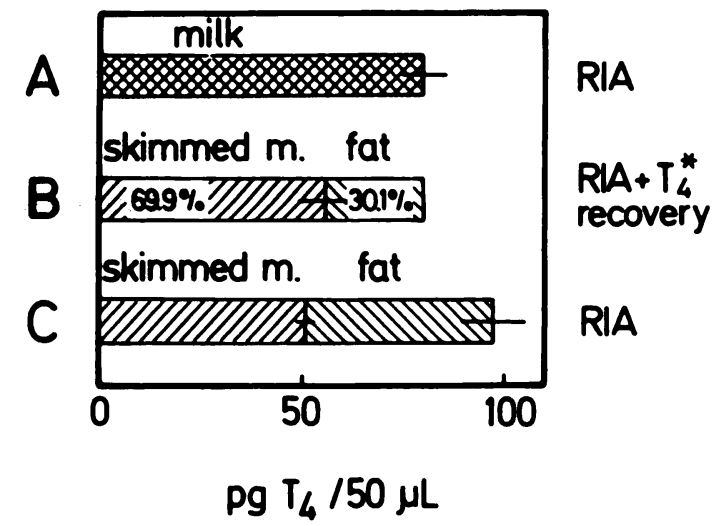

Fig. 3. Comparison of found and calculated $\mathrm{T}_{4}$

Bar $A$, the apparent amount of $T_{4}$ in $50 \mu \mathrm{L}$ of whole milk, as determined by RIA Bar $B$, amounts of $T_{4}$ that should have been found in skimmed milk and in millk fat, as calculated from the data found in $A$, and the individual pertition coefficients of the added $T_{4}^{*}\left(69.9 \pm 4.9 \%\right.$ of $T_{4}^{\circ}$ in skimmed milk and $30.1 \pm 4.9 \%$ in fat). Bar $C$, amounts actually found by RIA on using $50 \mu \mathrm{L}$ of skimmed milk or the fat in $50 \mu \mathrm{L}$ of whole milk, corresponding to the four samples used for Fig. 1

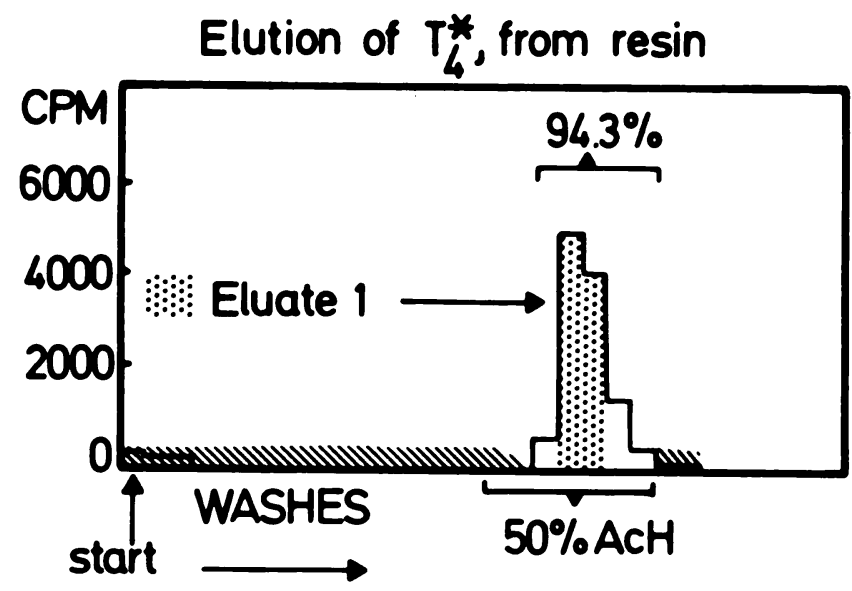

\section{Paper chromatography of Eluate 1}

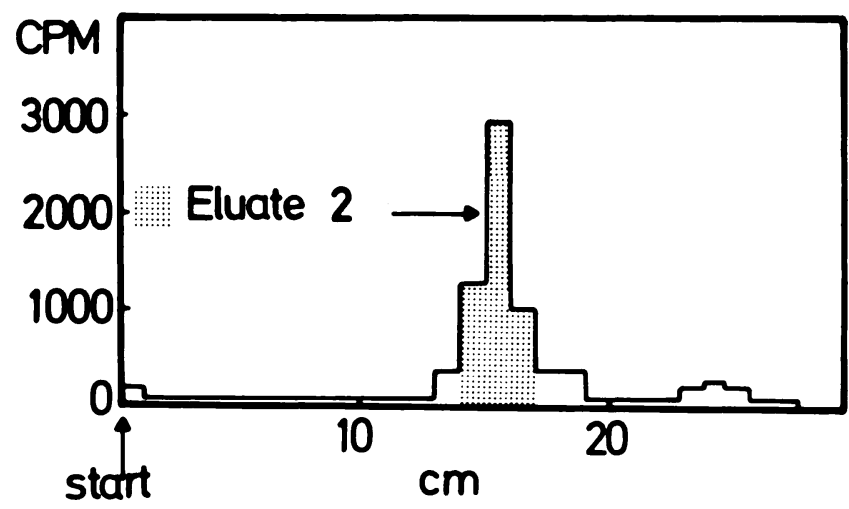

Fig. 4. Upper panel: the pattern of elution of $T_{4}^{*}$ added to human milk, after passing it through Bio-Rad columns and the successive washes described here

Practically all of the $\mathrm{T}_{4}^{\circ}$ is eluted with acetic acid (AcH), $500 \mathrm{~mL} / \mathrm{L}$. Fractions are of $0.5-\mathrm{mL}$ volume. Eluate $1 \mathrm{is}$ formed by pooling the two fractions with the highest $T_{4}$ i content so that $40-80 \mu \mathrm{L}$ of milk equivalents will require minimum volumes of Eluate 1. The shaded area indicates fractions with high turbidity, or opalescence. Most of the "milky" components are eluted in the first washes, but the first fractions eluting with AcH are not completely clear. When the column is further washed with $700 \mathrm{~mL} / \mathrm{L}$ Act, the first eluates are again opalescent. Care is taken to choose for eluate 1 those fractions with a high $T^{\circ}$ content that are most transparent. No visible residue remains in the RIA tubes after evaporation of $40-80 \mu \mathrm{L}$ of eluate 1

Lower panel: the pattern of distribution of $\mathrm{T}_{4}^{\circ}$ contained in eluate 1 after ascending paper chromatography (13)

The $\mathrm{T}_{4} i$ in the strips indicated by the shaded area is eluted and pooled to obtain eluate 2 
We observed that the apparent $T_{4}$ concentration also depended on the pretreatment given the sample (Table 1): the lower apparent $\mathrm{T}_{4}$ values found for 1:2 $\mathrm{EtOH}$ as compared with 1:10 EtOH extracts could not be accounted for by the $\mathrm{T}_{4}^{*}$ extraction coefficient, which exceeded $91 \%$ in both cases. Thus the difference persists when the $\mathrm{T}_{4}$ concentration in whole milk is calculated; the fat also appeared to contain significantly more $T_{4}$ than expected from the $T_{4}^{*}$ partition coefficient (column B of Table 1). We noticed that a layer of fat was visible in 1:2 EtOH extracts of whole milk, but not in the 1:10 EtOH extracts; evidently more fat was being dissolved in 1:10 than in 1:2 EtOH extracts. Milk fat separated from whole milk by centrifugation was also completely dissolved in EtOH.

The sum of the apparent amounts of $\mathrm{T}_{4}$ found in skimmed milk and milk fat exceeds that found in whole milk (Figure 3). When the $T_{4}^{*}$ partition coefficients were applied to the $T_{4}$ data found for whole milk, the calculated amount of $\mathrm{T}_{4}$ and that actually measured by RIA coincided for the skimmed milk fraction. In contrast, the amount measured by RIA for the milk fat significantly exceeded the calculated one.

We considered the possibility that these problems were caused by the presence of moieties binding the labeled antigen, especially when the lipid content of the sample transferred to the RIA is high, because the use of skimmed milk did not solve all the problems encountered. To assess such possibilities we evaluated the nonspecific binding of $T_{4}^{*}$. Table 2 shows results obtained with both PEG and $S$. aureus. Nonspecific binding of $T_{4}^{*}$ was often greater in samples derived from milk than in RIA buffer alone, and often appeared related to the probable fat content of the sample (column $B$ of Table 2). Nonspecific binding by $S$. aureus could be as great as total binding in samples likely to contain a high proportion of milk fats.

The lipophilic nature of $\mathrm{T}_{4}$ made it unlikely that solventextraction procedures would adequately separate it from lipidic milk components. Paper chromatography was initially attempted with whole milk, skimmed milk, and EtOH extracts, but good separations were not consistently obtained. Bio-Rad resin columns (12) were used and preliminary ex- periments done to define the appropriate volumes of mill relative to the amount of resin and the procedure that would elute most of the $\mathrm{T}_{4}$ in a clear, non-opalescent fraction. Procedure $B$ was developed and initially validated with procedure $\mathrm{C}$, which involves paper chromatography of the resin eluate.

Figure 4 shows elution patterns of $\mathrm{T}_{4}^{*}$ after its adsorption on a Bio-Rad resin column and after paper chromatography of the resin eluate. Good parallelism was found between the $\mathrm{T}_{4}$ standard curves and serial dilutions of both eluates 1 and 2 (Figure 5). The eluates from the "blank" columns did not interfere in the $T_{4}$ RIA. Figure 6 confirms, for both eluates 1 and 2 , that the $T_{4}$ concentration is no longer dependent on the volume of sample in the RIA tube. The nonspecific binding of $\mathrm{T}_{4}^{*}$ as evaluated with eluate 2 was the same as that of the standard curve blanks (Table 3), but specific binding with eluate 1 was somewhat higher. Despite this, when we used the individual blanks to calculate the $T_{4}$ concentration, the results obtained with eluates 1 and 2 were the same (Figure 6).

Individual blanks increase with the amount of eluate 1 used in the RIA. If large volumes of eluate 1 are needed because of a low $\mathrm{T}_{4}$ concentration in the milk sample, procedure $\mathrm{C}$ should be followed. The same is advisable if individual blanks for eluate 1 are unusually high. Procedure B should not be altered without previous validation. Thus, an increase in the volume of milk relative to that of the resin bed would decrease the proportion of $\mathrm{T}_{4}$ retained on the column and later eluted with acetic acid/water (1/1 by vol). A decrease in the amount of milk used relative to that of resin bed would result in the use of larger aliquots of eluate 1 , a procedure that should be avoided for the reason indicated above.

Figure 7 shows our preliminary frequency distribution of the $\mathrm{T}_{4}$ concentrations in human milk. Most of the samples were obtained two or three weeks postpartum. As may be seen. in none of the samples tested so far did the $\mathrm{T}_{4}$ concentration exceed $2 \mu \mathrm{g} / \mathrm{L}$.

\section{Discussion}

Our results show that human milk contains substances that interfere with $\mathrm{T}_{4}$ RIA in proportion to the volume of milk

\section{ELUATE 1}

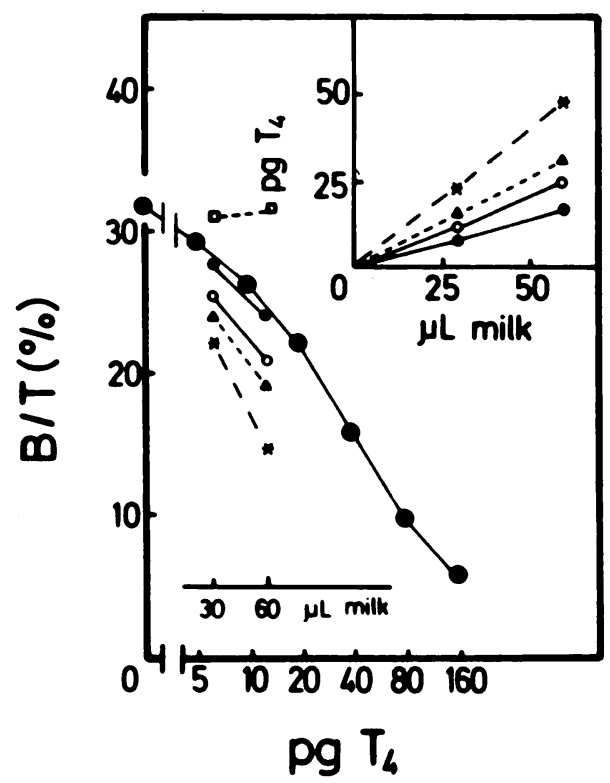

ELUATE 2

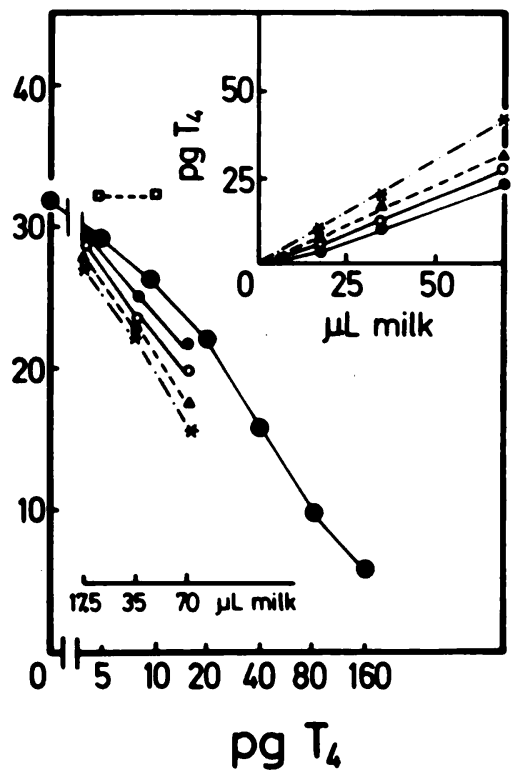

Fig. 5. Serial dilution curves obtained with eluates 1 and 2

For the sake of simplicity, the milk volumes shown are the approximate means corresponding to 40 and $80 \mu \mathrm{L}$ of eluate 1, or 20,100 , and $200 \mu \mathrm{L}$ of eluate 2, as assessed from individual $T_{4}^{*}$ recoveries. The actual mean values are given in Table 3 . Different symbols are used to identify milk specimens (different from those used for previous Figures and Tables). (口 - . - ם), results obtained for eluates 1 and 2 from "blank" columns 


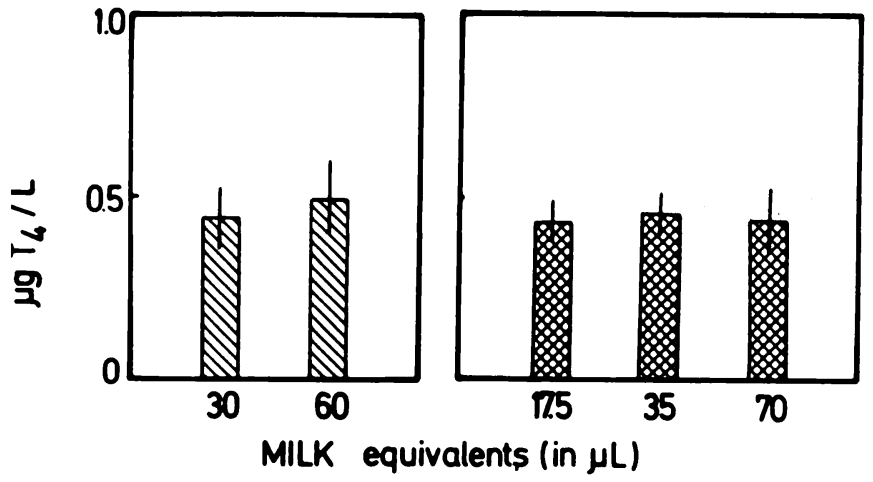

Fig. 6. $T_{4}$ concentrations found on different volumes of milk equivalents for the RIA

Results no longer depend on sample volume, and are the same whether the resin eluate is further purified by paper chromatography (right, eluate 2) or not (left, eluate 1)

required for the RIA. Previous studies reporting $\mathrm{T}_{4}$ concentrations $>5 \mu \mathrm{g} / \mathrm{L}(1-4)$ were done with less-sensitive competitive binding or radioimmunoassays that required larger sample volumes ( $100 \mu \mathrm{L}$ or more). Thus it is likely that those results were artifactual, a possibility apparently not excluded by the authors, because they report no validation tests, such as serial-dilution curves and the like. The use of skimmed milk or EtOH extracts as samples would not necessarily obviate these artifacts, as shown here.

Tenore et al. (16) reported that there might be analytical problems with the determination of $T_{4}$ by RIA: $T_{4}^{*}$ displacement activity in the $\mathrm{T}_{4}$ RIA did not coincide, after chromatography on Sephadex LH 20, with the fractions eluting the radiolabeled $\mathrm{T}_{4}$ added to the milk sample as tracer. The RIA activity was eluted in the void volume, where no labeled $\mathrm{T}_{4}$ was found, whereas no RIA activity was found in the peak containing tracer $\mathrm{T}_{4}$. In view of our results perhaps the amounts of $\mathrm{T}_{4}$ eluted in the fraction containing the tracer $\mathrm{T}_{4}$ were too small to be detected by RIA, and the "radioimmunoassayable activity" they found in the void volume actually reflected the presence of moieties interfering in the $T_{4}$ RIA.

The interpretation suggested by these authors was, however, that endogenous $\mathrm{T}_{4}$ did not equilibrate with the added labeled $\mathrm{T}_{4}$. If this were so, values obtained with our procedures $B$ and $C$ might be underestimated. But we believe that the data in Figure 3 show this to be unlikely, because the amount of $\mathrm{T}_{4}$ in the skimmed-milk fraction coincided with the one calculated from the whole-milk $T_{4}$ content and the $T_{4}^{*}$ partition coefficient. In contrast, the amount of $T_{4}$ in the fat layer

\footnotetext{
Table 3. Binding of $T_{4}^{*}$ in the Absence of Anti-T Antiserum in RIA Tubes Containing Different Volumes of Eluates 1 and 2 from Seven Different Milk Specimens "

\begin{tabular}{|c|c|c|c|}
\hline Sample & $\begin{array}{c}\text { Eluate } \\
\text { ovaporated, } \mu L\end{array}$ & $\begin{array}{l}\mu L \text { of millk } \\
\text { equilvalent }\end{array}$ & $\begin{array}{c}\% \text { of } T_{i}^{\circ} \\
\text { (nonepectilic binding) }\end{array}$ \\
\hline RIA buffer ${ }^{c}$ & - & - & $7.0(0.2)$ \\
\hline Eluate 1 & 40 & $28.4(4.2)$ & $8.5(0.5)^{d}$ \\
\hline Eluate 1 & 80 & $56.8(4.2)$ & $10.0(0.4)^{d}$ \\
\hline Eluate 2 & 50 & $17.8(5.9)$ & $7.1(0.1)$ \\
\hline Eluate 2 & 100 & $35.7(5.9)$ & $7.4(0.5)$ \\
\hline Eluate 2 & 200 & $71.4(5.9)$ & $7.8(1.3)$ \\
\hline
\end{tabular}

- Data are means (and SEM), with separation by PEG. 'The mean (and SEM) of the equivalemt amounts of milk, based on the individual $T_{4}^{*}$ recovery data. $c$ The total binding in the presence of anti- $T_{4}$ antibody was $39.1 \pm 0.4 \%$. ${ }^{\circ}$ Difference with respect to the RIA buffer (standard curve blanks) is statistically significant.
}

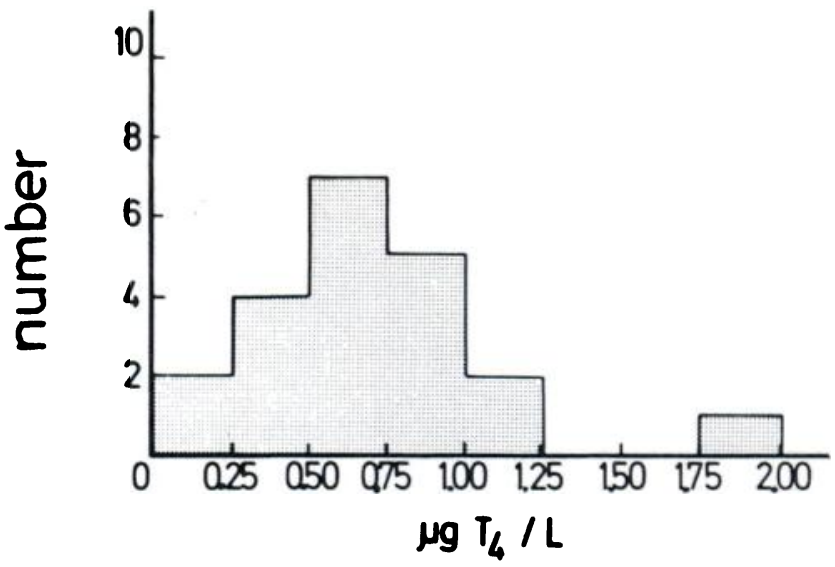

Fig. 7. Distribution curve of $T_{4}$ concentration found in 21 samples of human milk, most of which were obtained two to three weeks postpartum

The mean value $( \pm S E M)$ was $0.71 \pm 0.09$ (range $0.24-2.00) \mu g / L$

did not correlate, probably because of the presence of interfering moieties. The sum of the $T_{4}$ found in the skimmed milk plus that in the fat layer should have been the same as the $T_{4}$ found in whole milk if the only problem were a lack of equilibration of added $T_{4}^{*}$ with the endogenous $T_{4}$.

Apart from interferences apparently related to its high lipid content, human milk might contain thyroxin-binding proteins; corticosteroid-binding globulins have been identified in human and rat milk, and are apparently identical to the binding proteins in serum $(17,18)$. This might also affect the RIA results, because the amounts of "blockers" added for the determination of $\mathrm{T}_{4}$ in serum might not be adequate.

Procedures $\mathrm{B}$ and $\mathrm{C}$ are currently being validated for the determination of $\mathrm{T}_{4}$ in sera and tissues with a high lipid content.

Our results are in essential agreement with the reports by Varma et al. (5), Sato and Suzuki (6), and Tsuyusaki et al. (7). In view of the results by Sato and Suzuki (6) for trypsin digests of human milk, it is unlikely that the total $\mathrm{T}_{4}$ content exceeds $5 \mu \mathrm{g}$ of $\mathrm{T}_{4}$ per liter. Thus, unless human milk contains high concentrations of $T_{3}$, which is unlikely (6), the thyroid hormone content of human milk would not afford adequate protection to the developing brain of athyreotic babies.

The reported improved mental development of breast-fed as compared with formula-fed hypothyroid babies (4) might be related to some other nutritional difference, such as the iodine content (19). The human baby depends totally on the iodine in milk for thyroid function during the suckling period; ectopic thyroid tissue might function longer if the iodine supply is adequate.

This work was supported by funds from Caja de Ahorros y Monte de Piedad de Madrid, and from Comision Asesora para Investigación Cientifica y Tecnica (Spain). We are grateful to Dr. I. Gil (Instituto de Inmunologia, C.S.I.C., Madrid) for the preparation of Staphylococcus aureus, and to Ms. S. Duran for technical assistance.

The work was presented at the XI Meeting of the European Thyroid Association, Pisa, 1981. J.M. is the recipient of a fellowship from Caja de Ahorros y Monte de Piedad de Madrid.

\section{References}

1. Montalvo, J. M., Wahner, H. W., and Christie, R. J., Triiodothyronine and thyroxine levels in breast milk of humans and primates. 56th Meeting of the Am. Endocrine Soc., Atlanta, GA, 1976, p A-91. Abstract.

2. Strbák, V., Macho, L., Kováč, R., et al., Thyroxine by competitive protein binding analysis in human and cow milk and in infant formulas. Endocrinol. Exp. 10, 167-174 (1976). 
3. Sack, J., Amado, O., and Lunenfeld, B., Thyroxine concentration in human milk. J. Clin. Endocrinol. Metab. 45, 171-173 (1977).

4. Tenore, A., Parks, J. S., and Bongiovanni, A. M., Relationship of breast feeding to congenital hypothyroidism. In Recent Progress in Pediatric Endocrinology (Serono Sympos., Vol. 12), 1977, pp 213218.

5. Varma, S. K., Collins, M., Row, A., et al., Thyroxine, triiodothyronine and reverse-triiodothyronine concentrations in human milk. J. Pediatr. 93, 803-806 (1978).

6. Sato, T., and Suzuki, Y., Presence of triiodothyronine, no detectable thyroxine and reverse triiodothyronine in human milk. Endocrinol. Jpn. 26, 507-513 (1979).

7. Tsuyusaki, T., Sasaki, N., Miyamoto, S., et al., 12th Annu. Meeting Jpn. Pediatr. Endocrinol. Soc., 1978.

8. Weeke, J., and Orskov, K., Evaluation of thyroid function. Rec. Adv. Clin. Biochem. 1, 111-128 (1978).

9. Obregón, M. J., Pascual, A., Mallol, J., et al., Evidence against a major role of L-thyroxine at the pituitary level: Studies in rats treated with iopanoic acid. Endocrinology 106, 1827-1836 (1980).

10. Weeke, J., and Orskov, K., Synthesis of ${ }^{125}$ I monolabeled 3:5:3'triiodothyronine and thyroxine of maximum specific activity for radioimmunoassay. Scand. J. Clin. Lab. Invest. 32, 357-360 (1973).

11. Kjeld, J. M., Kuku, S. K., Diamant, L., et al., Production and storage of ${ }^{125 I}$-thyroxine and ${ }^{125 I}$-triiodothyronine of high specific activity. Clin. Chim. Acta 61, 381-389 (1975).

12. Galton, V. A., and Pitt-Rivers, R., A quantitative method for the separation of thyroid hormones and related compounds from serup and tissues with an anion-exchange resin. Biochem. J. 72, 310-318 (1959).

13. Bellabarba, D., Peterson, R., and Sterling, K., An improved method for the chromatography of iodothyronines. J. Clin. Endocrinol. Metab. 28, 305-307 (1968).

14. Kessler, S. W., Rapid isolation of antigens from cells with staphylococcal protein A-antibody adsorbent: Parameters of the interaction of antigen-antibody complexes with protein A. J. Im munol. 115, 1617-1624 (1975).

15. Snedecor, G. W., Statistical Methods, 5th ed., Iowa State Uni versity Press, Ames, IA, 1956.

16. Tenore, A., Koldovsky, O., Parks, J. S., et al., Problems in the measurement of thyroid hormones in milk. 60th meeting Am. Endocrine Soc., 1978, Miami, FL. Abstract 91.

17. Rosner, W., Beers, P. C., Awan, T., and Khan, M.S., Identificatio of corticosteroid-binding globulin in human milk: Measurement wit a filter disk assay. J. Clin. Endocrinol. Metab. 42, 1064-107\$ (1976).

18. Pearlman, W. H., Skrzynia, C., Hampel, M. R., et al., The leved of corticosterone-binding proteins in rat milk and coincidental serum, and the dissociation rates of the corticosterone-protein complexes Endocrinology 108, 741-746 (1981).

19. Mallol, J., Obregón, M. J., and Morreale de Escobar, G., Deter minación de iodo y tiroxina en leche humana y maternizada. XX Reunión de la Sociedad Española de Endocrinologia, Palma de Mallorca, 1981. 